\title{
О ЗНАЧЕНИИ ФРАГМЕНТА СОСУДА В ПОГРЕБАЛЬНОМ ОБРЯДЕ \\ АЛАКУЛЬСКОЙ КУЛЬТУРЫ ИЛИ «ШАШУ» ПО-АНДРОНОВСКИ (ПО МАТЕРИАЛАМ МОГИЛЬНИКА НОВОИЛЬИНОВСКИЙ ІІ, КАЗАХСТАН)
}

\author{
Эмма Радиковна Усманова \\ Карагандинский университет им. академика Е.А. Букетова, Караганда, Казахстан \\ E-mail: emmadervish2004@mail.ru \\ Зубайда Кабиевна Сураганова \\ Гос. историко-культурный музей-заповедник «Бозок», Нур-Султан, Казахстан \\ E-mail: suraganova_zk@mail.ru
}

Аннотация. В системе погребального обряда алакульской культуры есть компонент, который, на первый взгляд, кажется незначительным по своему способу оформления по сравнению с другими предметами погребального инвентаря. Это фрагмент керамики. Он присутствует в погребальном сооружении как самостоятельное ритуальное явление. Глиняные черепки приносились в погребальное пространство и использовались во время исполнения погребального обряда. На могильнике Новоильиновский II зафиксировано три варианта местонахождения фрагментов керамики: в погребении, во рву, в ритуальной яме. В основном, керамика принадлежит алакульской культуре. В статье описываются способы помещения и общий вид фрагментов в ритуале. Как правило, они принадлежали сосудам хозяйственного назначения, края и поверхность имели затертость, следы нагара. Вероятно, фрагменты керамики от разбитых при употреблении в хозяйстве сосудов, собирались и хранились на поселении. Во время совершения погребального обряда они приносились в погребальное пространство для ритуальных манипуляций. Известен случай, когда фрагменты керамики от сосудов синташтинской культуры были сброшены в погребение с керамикой петровской культуры, последующей за синташтой. На основании этнографических параллелей предлагается реконструкция ритуальной ситуации на могильнике Новоильиновский II, связанная с символикой глиняного черепка в обрядах жизненного цикла. Черепок от глиняного горшка в традиционных культурах используется как оберег, как знак благополучной жизни молодожёнов, с пожеланиями большего количества детей. Разбитый сосуд индексирует переход индивида из одного социального статуса в другой. В этнографии известна и коммуникативная функция фрагмента керамики в погребальном обряде, который отражает связь между миром живых и миром мертвых. В погребальном сооружении разбитые фрагменты сосудов фиксируются в разбросанном состоянии. По аналогии с народным казахским обычаем «шашу»-разбрасывание сладостей, баурсаков (кусочки жареного теста), как способа передачи благодати и оберега - сделано предположение о существовании ритуала разбрасывания глиняных черепков в андроновской погребальной практике.

Ключевые слова: фрагмент керамики, ров, ритуальная яма, погребальный обряд, битье сосуда, шашу

Цитирование. УсмановаЭ.Р., Сураганова 3.К., 2021. О значении фрагмента сосуда в погребальном обряде алакульской культуры или «шашу» по-андроновски (по материалам могильника Новоильиновский II, Казахстан) // Уфимский археологический вестник. Т.21, № 2. C.322-330. DOI: https://doi. org/10.31833/uav/2021.21.2.010

Благодарности. Работа выполнена по грантам Министерства культуры и спорта Республики Казахстан № BR10164218 «Традиционная обрядность как манифестация помнящей культуры: ресурсы и стратегии символического капитала степной Евразии».

UDC 393.05.951

Submitted: 06.09.2021

LBC 63.4(3)

Accepted: 10.11.2021

\section{ON THE MEANING OF POTTERY FRAGMENTS IN THE FUNERARY RITE OF THE ALAKUL CULTURE OR THE "SHASHU" OF THE ANDRONOVO TYPE (BASED ON THE ARTIFACTS FROM NOVOIL'INOVSKY II NECROPOLIS, KAZAKHSTAN)}

\author{
Emma R. Usmanova \\ Karaganda State University, Karaganda, Kazakhstan \\ E-mail: emmadervish2004@mail.ru \\ Zubaida K. Suraganova \\ State Historical and Cultural Museum-Reserve Park "Bozok", Nur-Sultan, Kazakhstan \\ E-mail: suraganova_zk@mail.ru
}

\begin{abstract}
The aim of this paper is to reflect on the role and functions of pottery fragments in the funerary rite of the Alakul culture on the basis of the artifacts recovered in Novoil'inovsky II necropolis (Kostanay region, Kazakhstan). Pottery fragments are viewed as an important element of the Alakul funerary rite, playing
\end{abstract}


an independent ritual role in the process. Analysis of findings from the burials suggests that pottery fragmentation was not performed during the funerary rite. Instead of this pottery fragments were collected in advance and specially brought to the ritual site. The studied Novoil'inovsky II necropolis displays three main locations of pottery fragments: in the grave, in the ditch and in the burial pit. Most fragments discovered in the two later locations show the same features: no decoration, chipped rims and body, thick walls containing traces of fire. They could be interpreted as parts of pottery vessels used for everyday purposes like food cooking and transportation. Most likely such fragments were collected by settlers after pottery smashing to be later used in the funerary rite. Pottery fragments found at Novoil'inovsky II necropolis are widely spread around the territory of necropolis. Such pattern points to the presence of a mortuary ritual in the Andronovo culture, in which the pottery fragments were scattered around the grave. Similar rituals (called "shashu") could be found in the traditional Kazakh culture. There people throw around small pieces of fried dough, spreading joy and blessing. Ethnographic evidence suggests that, pottery fragments have a symbolic meaning in life cycle rituals, marking a transition of a person from one stage of life to another, playing a role of a talisman, which gives an opportunity to increase wealth and happiness. In the rites of passage such as wedding of funerals pottery fragments function as a symbol of change in an individual's social status. It is considered that in the Bronze Age funerary rite pottery fragment served as a symbolic medium between the living and the dead. It was an archetype of culture, born in the depths of the archaic rituals.

Keywords: pottery fragment, ditch, burial pit, funerary rite, pottery smaching, shashu

Citation. UsmanovaE., SuraganovaZ., 2021. On the meaning of pottery fragments in the funerary rite of the Alakul culture or the "shashu" of the Andronovo type (based on the artifacts from Novoil'inovsky II necropolis, Kazakhstan). Ufimskij arkheologicheskiy vestnik [The Ufa Archaeological Herald]. Vol.21, no.2, pp.322-330. (In Russ.). DOI: https://doi.org/10.31833/uav/2021.21.2.010

Acknowledgements. This work is supported by the Ministry of Culture and Sport of the Republic of Kazakhstan under the grant №BR10164218 "Traditional rituals as a manifestation of a commemorative culture: resources and strategies of the symbolic capital of the steppe Eurasia".

\section{Разбить - счастье нажить \\ Русская пословица \\ Посуда бьётся - жди удач <...> Автор слов Ю.Энтин}

Посвящается моему главному учителю в археологии - Г.Б. Здановичу. В далекие 70-годы прошлого столетия подростком я пришла в кружок «Юный археолог», который существовал во Дворие пионеров и школьников г. Караганды в составе «Научного общества учашихся». Геннадий Борисович учил нас школьников мыслить. Не списывать, а самим собирать информаџию и превращать ее в мысль, которая дает развитие интеллекту. В археологии он считал главным правилом исследования - умение видеть за любым артефактом харизму ушедших культур и человека, с его представлением об окружающим мире. Спасибо, Учитель! Следую этому главному правилу, которому научил меня Г.Б. Зданович.

Эмма Усманова

\section{Введение}

«Сосуд занимает особое место среди компонентов погребального комплекса, что определено, в первую очередь, его полифункциональностью» [Полидович, 2005. С.198]. Сосуд - хранитель пищи, которая готовится в нем; участник ритуалов; структурно-организующий предмет, чья форма и орнаментация обладают внутренней силой и способствуют к воздействию на что-то и достижению чего-то. Иными словами, сосуд в составе погребального инвентаря имеет утилитарное (пассивное начало), ритуальное (активное начало) и магико-символическое значение [Полидович, 2005. C. 198].

В андроновской погребальной традиции посуда, главным образом, была глиняной, которая и сохраняется в погребениях. Керамический сервиз - это основной элемент в андроновском погребальном инвентаре. Посуда имеет отношение к быту, хозяйству, жилищу, пище. Она является обязательным элементом домашней среды, легко пе- редвигаема и переносима в пространстве. Отсюда, видимо, следует ее символическая связь между домом «живых» и домом «мертвых», коим является погребение.

В погребениях часто фиксируются в сосудах следы пищи в виде нагара, потеков жидкости на поверхности, известны находки костей животных внутри глиняной емкости. Таким образом реализуется пассивное начало сосуда в погребальном обряде. Скорее всего, сосуды, выставленные в погребениях и жертвенниках, использовались в быту и хозяйстве. Но также не надо исключать, что некоторые из них могли быть специально изготовлены для обрядовых целей. Сосуд, поставленный в погребальную камеру (например, на дно, вверх дном, на боку), находясь в разных положениях относительно тела умершего, представляет свою активную позицию участника ритуальных манипуляций. Форма и орнамент демонстрируют семантический потенциал сосуда - символический текст, который «содержится» на его поверхности. 
Если при намеренном проникновении в могильную яму сосуды не были разбиты, то. как правило, они предстают перед исследователями археологически целыми.

Другое дело - отдельные фрагменты керамики, разбитые черепки от сосудов, которые попадаются в насыпи сооружения, в заполнении рвов, ям и погребений. В контексте обряда они имеют самостоятельное значение и никоим образом не относятся к сосудам, которые помещались в погребении или жертвенник, или могли разбиваться следуя правилам ритуала. Глиняный черепок от разбитого горшка в обряде изменяет свою рядовую бытовую сущность, переходя в сферу сакрального и приобретает новый знаковый смысл.

Итак, предметом нашего исследования являются фрагменты керамики из погребальных сооружений петровской и алакульской культур могильника Новоильиновский II ( лина, Костанайская обл., Казахстан) [Снитковская, Усманова, 2019].

\section{Археологические сюжеты}

Предварительно выделены три варианта местонахождения фрагментов керамики в погребальном пространстве:

- заполнение погребения;

- заполнение и дно рва;

- заполнение и дно ритуальной ямы.

Вариант первый. Фрагмент

керамики в заполнении погребения

$\mathrm{B}$ заполнении могильной ямы были обнаружены фрагменты от пяти разных сосудов синташтинского типа (могильник Новоильиновский II, курган №4, погребение №1). Четыре фрагмента имели сквозные ремонтные отверстия (рис. 1). На дне погребения было зафиксировано три сосуда петровского и алакульского облика (рис. 2, 1). Скорее всего, фрагменты синташтинской керамики были закинуты в могилу при совершении ритуала. Следует отметить особенность погребения: в него было совершено намеренное проникновение, при котором погребальный инвентарь (костяные крючок, пряслице, проколка и игольница, бронзовые шило и нож, точильный камень) остался in situ. Головной убор и украшения были сняты с тела умершей женщины, их фрагменты обнаружены около черепа.

Другая особенность этого погребения - это остатки столбовой конструкции на дне могильной ямы [Снитковская, Усманова, 2019. С.80. Рис. 3]. По углам и посередине западной и восточной стенок располагалось шесть столбовых ямок, вероятно, входивших в систему опоры для перекрытия (рис. 2, 2). Скорее всего, оно было снято после завершения всего обрядового цикла, куда, возможно, и входило намеренное проникновение с целью ритуального изъятия украшений. После того как убрали столбы перекрытия, могила была засыпана грунтом вместе с фрагментами синташтинской керамики.
Глиняный черепок как тетоria. При визуальном рассмотрении фрагментов керамики синташтинской культуры было отмечено, что они отличаются по керамическому тесту и технологии изготовления от сосудов петровской и алакульской культур, поставленных на дно погребения. Скорее всего, они были сделаны в другой местности. Неоднократный ремонт сосудов, хранение от них фрагментов, после того как они разбились, и помещение глиняных черепков в погребальное пространство другой культуры - все это говорит об их значимости в обрядовой жизни местного сообщества. Не исключено, что черепки от синташтинских сосудов были привнесены людьми в новую среду обитания. Кстати, это пока единственный зафиксированный случай присутствия синташтинской керамики в виде фрагментов на могильнике Новоильиновский II, где большинство погребений относятся к алакульской культуре, при наличии нескольких погребений с керамикой петровского облика.

Из-за набора вещей явно ткацкой специфики, данное захоронение получило символическое название «погребение ткачихи». Вероятно, значение фрагментов синташтинской посуды относится к проявлению знака памяти - связи с культурой предшествующего поколения. Символическая memoria предков, которая сохранилась в глиняном черепке от горшка.

\section{Вариант второй. Заполнение и дно рва}

Местонахождение фрагментов посуды известно во рвах (как правило, они все кольцевые, но есть полукольцевые, сегментовидные) погребальных памятников алакульских могильников Лисаковский округи (Лисаковский I-VII, Новоильиновский II). Всего известно 25 таких сооружений, из них 21 сооружение в своих рвах имело фрагменты

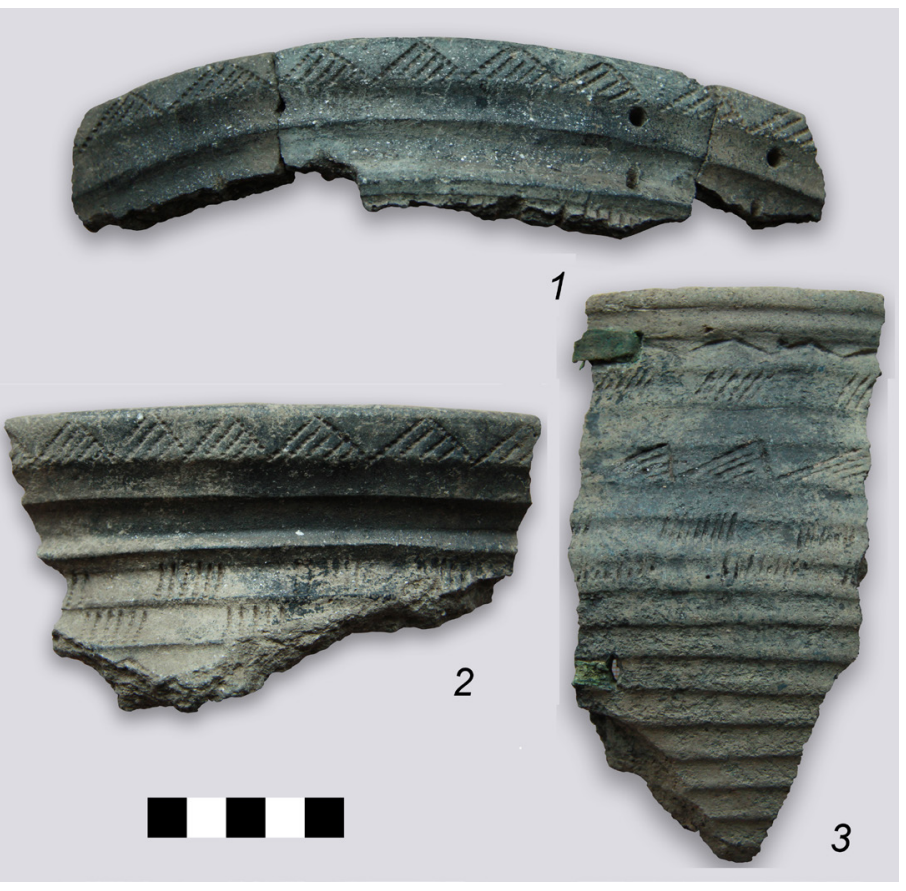

Рис. 1. Могильник Новоильиновский II. Курган №4. Фрагменты керамики синташтинской культуры. Фото Э.Р. Усмановой

Fig. 1. Novoil'inovsky II necropolis. Barrow №4. Pottery fragments of the Sintashta culture. Photo by E. Usmanova 
керамики [Усманова, 2005; Усманова, 2013]. Чаще всего во рву фиксируется по одному или по несколько фрагментов керамики. Иногда фрагменты выкладывались в определенном числовом ритме и на определенном расстоянии друг от друга: Лисаковский III, сооружение №4 [Усманова, 2013. С. 149. Рис. 7/14].

Глиняные черепки не относились к сосудам из погребений, разбитым при проникновении и чьи фрагменты могли быть выкинутыми в ров. Они имели собственное ритуальное содержание. Как правило, небольшие по размерам фрагменты принадлежали разным сосудам явно хозяйственного значения. Они имели затертые края и потертую поверхность, следы нагара на стенках. Фрагменты так называемой парадной, нарядной посуды, во рвах отсутствовали.

Известны скопления во рву из нескольких десятков фрагментов от различных сосудов (Новоильиновский II, ограда №6). Глиняные черепки в количестве около сорока штук были рассыпаны в виде прерывистой полосы по направлению дна рва (рис. 3,$2 ; 4,1$ ).
Скорее всего, они были принесены на погребальное поле с поселения, возможно, от горшков, разбитых в период их использования в хозяйстве и в быту. По нашим наблюдениям, посуда во рву специально не билась. В погребальном обряде употреблялись ранее разбитые фрагменты. Возможно, на поселении существовало место, где собирались и хранились черепки от разбитой посуды, чтобы далее их употребить в погребальном обряде. Скорее всего, по магическому замыслу они обозначали символическую связь живущих людей с их сородичами, ушедшими на свидание с вечностью.

\section{Вариант третий. Заполнение}

и дно ритуальной ямы

Так условно обозначается яма, в заполнении которой имеются фрагменты керамики, но отсутствует костяк и погребальный инвентарь. Подобная яма впервые была зафиксирована за пределами погребальной постройки на могильнике Новоильиновский II (курган №6). Яма овальной формы была оформлена по своим сторонам плашмя положенными камнями. С восточной стороны
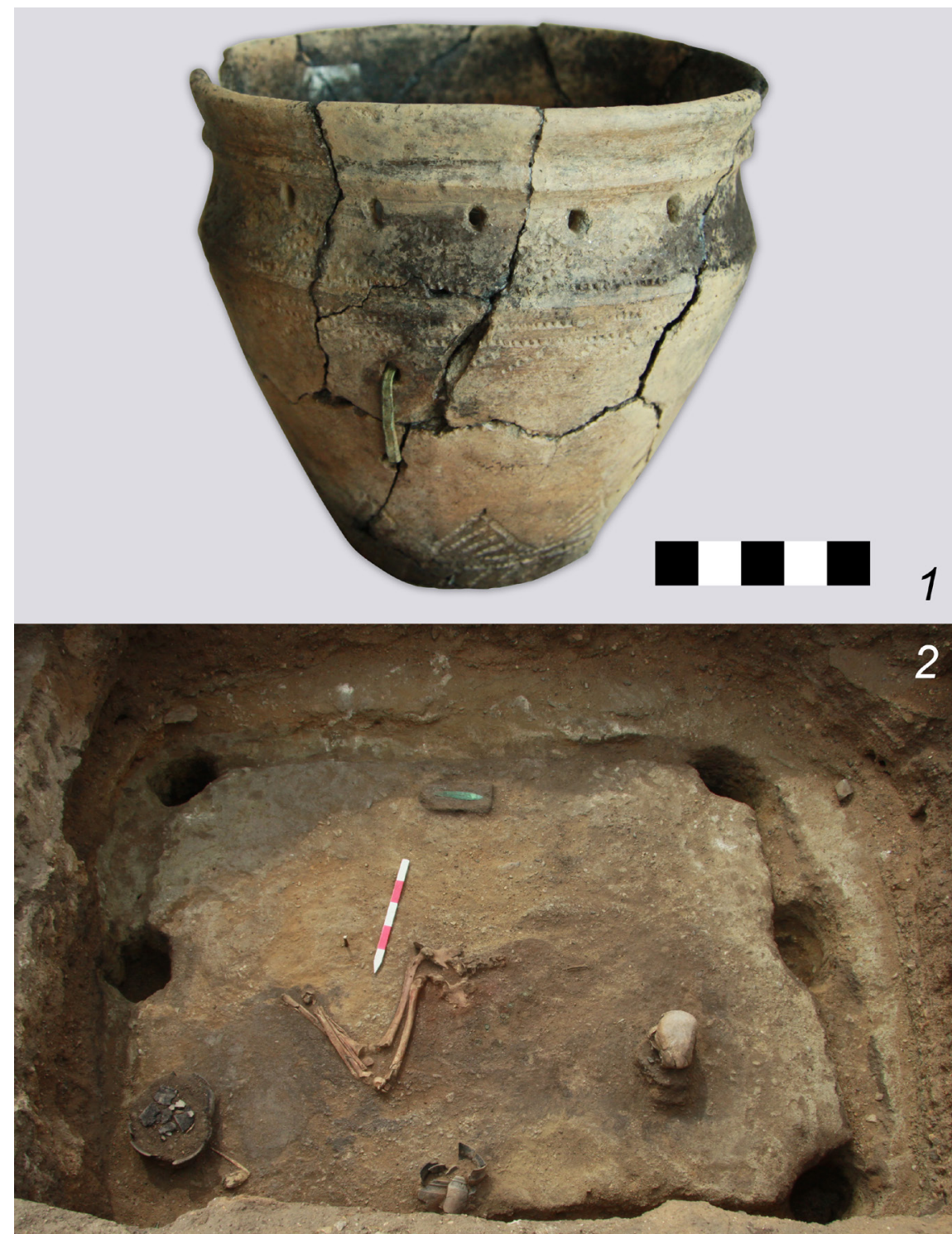

Рис. 2. Могильник Новоильиновский ІІ. Курган №4. 1 - сосуд петровской культуры; 2 - погребение № 1. Фото Э.Р. Усмановой

Fig. 2. Novoil'inovsky II necropolis. Barrow № 4.1 - pottery vessel of the Petrovka culture; 2 - burial № 1. Photos by E. Usmanova 
по направлению к яме имелся коридор длиной около двух метров, сложенный из нескольких камней, находящихся на расстоянии около 0,5-0,7 м друга от друга (рис. 4, 1).

В заполнении ямы на разных глубинах встречались отдельные фрагменты керамики и камни небольших размеров. Примечательно, что среди камней заполнения есть камни рубящего типа, которые, по всей видимости, предназначались для рытья ямы. По сторонам ямы имелся ступенчатый спуск ко дну (рис. 4, 2). Основное скопление фрагментов и камней было зафиксировано в придонной части ямы, где в центре имелось углубление овальной формы, оформленное вокруг белесым суглинком (рис. 5,1$)$.

Всего насчитывалось около сорока фрагментов керамики от четырех сосудов. Большинство из них неорнаментированные. Несколько фрагментов горловины орнаментированы в характерной манере алакульской культуры. Глиняные черепки размером 1,0-3,0 см имели затертые края и поверхность со следами нагара. Несколько фрагментов от придонной части сосуда относительно крупных размеров лежало непосредственно на дне ямы, на глубине около 1,0 м. По всей видимости, фрагменты забрасывались в определенной последовательности, начиная с центра дна ямы. Наиболее насыщенные фрагментами керамики слои заполнения относились к придонной части. Верхние слои содержали лишь единичные фрагменты керамики. Видимо, такая последовательность забрасывания фрагментов в яму была определена ритмом ритуала.

Можно предположить следующую реконструкцию ритуала: его исполнитель спускался на дно ямы, где вырывалось углубление (возможно, для возлияния какой-либо жидкости), которое обкладывалось по окружности суглинком белесого цвета, затем раскидывались фрагменты керамики. После того как исполнитель покидал яму, она засыпалась грунтом вместе с остальными глиняными черепками. Вероятно, какую-то роль в исполнении ритуала играл своеобразный коридор, по которому могли проходить участники церемонии для забрасывания керамики и грунта в яму. Возможно, таким образом демонстрировалась причастность к погребальной церемонии членов сообщества.

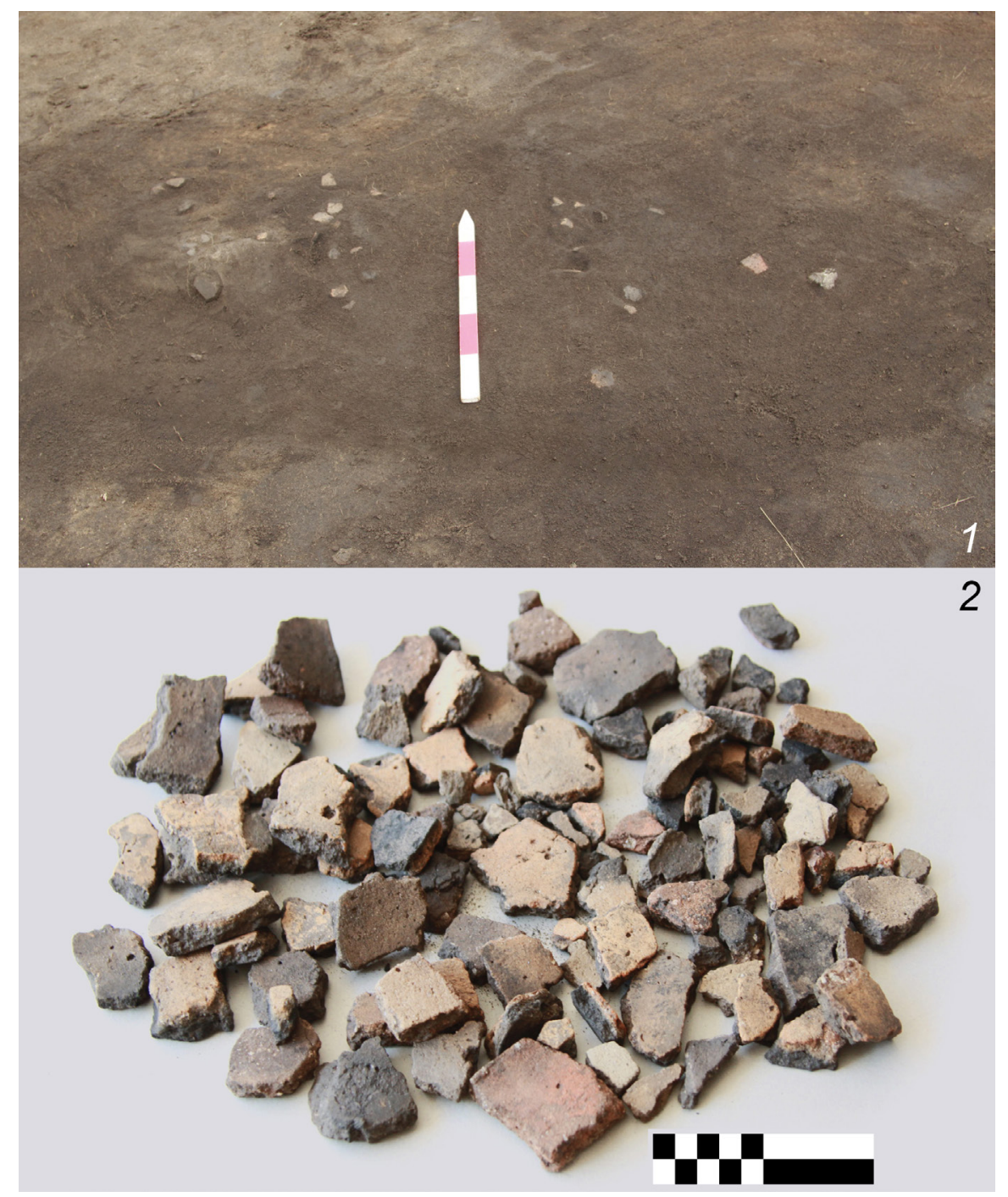

Рис. 3. Могильник Новоильиновский II. Курган №6. 1 - ров с фрагментами керамики; 2 - фрагменты керамики из рва. Фото Э.Р. Усмановой

Fig. 3. Novoil'inovsky II necropolis. Barrow №6. 1 - the ditch with pottery fragments; 2 - pottery fragments from the ditch. Photos by E. Usmanova 
Очевидно, что общих версий объяснения факта наличия подобной ритуальной ямы в системе погребального обряда можно набрать с десяток. Ясно то, что фрагменту керамики отводилась самостоятельная роль, определенная его символикой в погребальной церемонии. В этом контексте приведем некоторые этнографические параллели об использовании глиняных черепков в разных обрядах жизненного цикла.

\section{Этнографические сюжеты}

Битье посуды было необходимым моментом поведения в программе ритуалов обрядов перехода, среди которых известны свадебный и похоронный обряды, а также родины [Геннеп, 1999]. Разбитый сосуд олицетворяет изменение статуса человека, означает начало или конец какой-то ситуации и переход к следующей [Свешникова, Цивьян, 1973. С. 183]. Бить посуду - это значит разрушить старые связи и создать новые. Негативный аспект
- основательный слом предмета - в обряде заменяется на положительное значение. Особенно это явственно проявляется на свадьбе и похоронах.

Битый черепок «на счастье» на славянской свадьбе и крестинах ассоциируется с детьми «сколько черепков, столько сынков». Причём обилие черепков сулило жениху с невестой долгую и богатую жизнь. По славянским обычаям бьют горшок с кашей при переходе в новый дом, черепки закапывают в переднем углу как символ нового жилища [Байбурин, 1993. С. 172].

Оберег в виде черепков от разбитой посуды, который предотвращает болезни, известен у многих народов. Например, туркмены обкладывали больного человека глиняными черепками. У западных славян существовала традиция битьём горшка отпугивать болезни [Демидов, 1962. С. 209; Пошивайло, 1993. С.306].

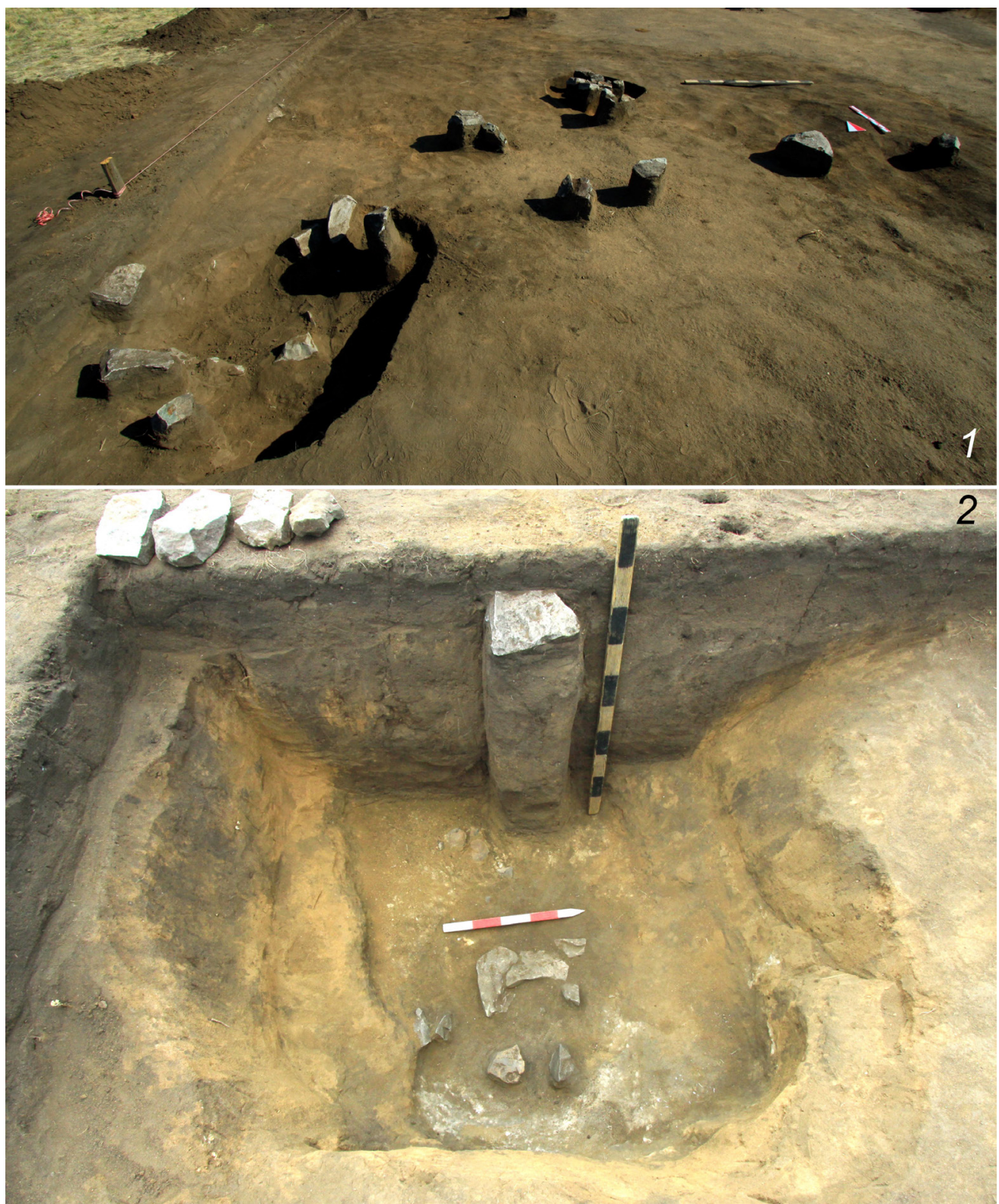

Рис. 4. Могильник Новоильиновский ІІ. Курган №6. 1 - вид ритуальной ямы до вскрытия; 2 - вид ритуальной ямы во время вскрытия. Фото Э.Р. Усмановой

Fig. 4. Novoil'inovsky II necropolis. Barrow №6. 1 - view of the burial pit prior to the excavation; 2 - view of the burial pit during the excavation. Photos by E. Usmanova 
Погребальная тризна, сопровождаемая битьем посуды, является ритуальной аксиомой, которая олицетворяет конец жизни человека, переход в другое состояние и одновременно фрагмент горшка - это символ непрекращающейся коммуникации между живыми и ушедшими на свидание с вечностью людьми. «К чисто южно-калифорнийским чертам культуры индейских племен можно отнести ежегодные или по крайней мере периодические поминальные церемонии, включающие битье глиняной посуды» [Даунс, 1978. С. 304].

В обрядах разбитые черепки от посуды, чаще всего, разбрасываются. Это еще одно действо, которое выражает символическое намерение в обрядовой программе. В этом контексте обратимся к известному казахскому ритуалу «шашу». В переводе с казахского языка это слово означает «разлить», «расплескать», «разбрызгать», «разбросать» чтолибо. По традиции у казахов осыпают индивида (-ов), проходящего (-их) обряд (-ы) жизненного и календарного цикла. В их число входят лиминальные обряды - mұсау кесер (ритуал разрезания пут у ребенка с тем чтобы стимулировать его к самостоятельному хождению), қыз ұзату той (проводы дочери), үйлену той (свадебный пир) и т. п.

Во время исполнения свадебного обряда в содержании «нұр жаусын» (пусть свет с небес прольется) благожелательной формулы ритуала шашу есть космогонический смысл: осыпание олицетворяет льющийся на молодых дождь, который по поверью должен принести им счастье [Аргынбаев, 1974. С.73]. Ритуал осыпания шаму в контексте традиционной культуры казахов рассматривается как ырымм - это «разные, имеющие магическое
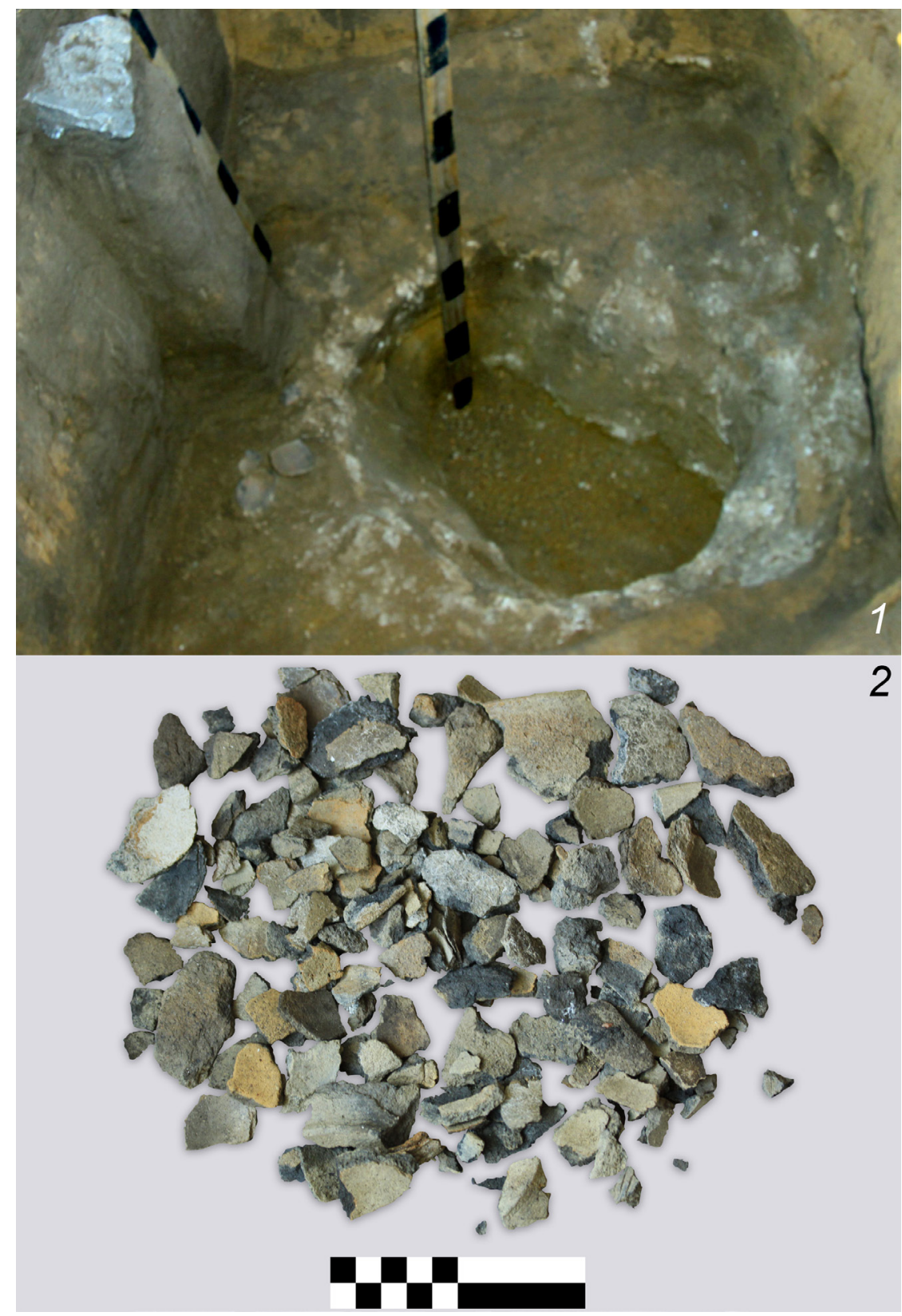

Рис. 5. Могильник Новоильиновский II. Курган № 6. 1 - вид дна ритуальной ямы; 2 - фрагменты керамики из ритуальной ямы. Фото Э.Р. Усмановой

Fig. 5. Novoil’inovsky II necropolis. Barrow №6. 1 - view of the bottom of the burial pit; 2 - pottery fragments from the burial pit. Photos by E. Usmanova 
значение, мелкие обряды и действия древнего происхождения, исполнение которых якобы принесет счастье, благополучие, удачу или же предотвратит неудачу и несчастье, а также всякие приметы, по которым следует действовать знающему их значение человеку при начинании или исполнении какого-либо дела» [Культура..., 1967. С. 226, 231]. В казахском языке yrym сохранилось в значении «поверье, примета, предзнаменование», его производное - ырылм-сырылм - подарки, связанные с народным ритуалом, обычаем и традицией. В хакасском языке ырымм означает «предсказание, пророчество», «счастье» [Бутанаев, 1999. С. 232]. Значение слова ырым переводится у казахов как «добрый знак или вообще примета, при каком-либо начинании или важном < ..> деле» [Герн, 1899. С. 13].

Итак, знаковый смысл ритуала шаму (разбрасывание) заключается в магии приношения удачи, благополучия, защиты от несчастья.

\section{Заключение}

«<..> социальная ситуация наделяет магические ассоциации определенным значением и позволяет им обрести частное выражение в той или иной культурной форме» [Эванс-Причард, 2003. C. 184-185]. Магическая формула pars pro toto - часть вместо целого - обозначает семантическую ценность фрагмента керамики в обрядовом пространстве. Разбитый сосуд на счастье, глиняный черепок - оберег, посредник между живыми и мертвыми - предметный архетип культуры, рожденный в глубине архаики обрядов, за которыми кроются ментальные черты поведения человека. Сосуд разбит, его фрагменты рассыпаны по земле, подобно семенам, дающим новую жизнь. По всей видимости, глиняный черепок в обрядах эпохи бронзы мог наделяться функциями памятного знака нового статуса, долгой жизни и благости, который до сих пор присутствует в обрядовой жизни этнографической современности.

\section{СПИСОК ЛИТЕРАТУРЫ}

АргынбаевХ. Свадьба и свадебные обряды у казахов в прошлом и настоящем // Советская этнография. № 6. 1974. С. 69-77.

Байбурин А.К. Ритуал в традиционной культуpe. Структурно-семантический анализ восточнославянских обрядов. СПб.: Наука, 1993. 253 с.

Бутанаев В.Я. Хакасско-русский историко-этнографический словарь. Абакан: Хакасия, 1999. $240 \mathrm{c}$.

Геннеп А., ван. Обряды перехода. Систематическое изучение обрядов. М.: Восточная литератуpa, 1999. $198 \mathrm{c}$.

Герн фон Вл. Из записной книжки. Этнографические заметки. Характер и нравы киргизов-казаков // Памятная книжка Семипалатинской области на 1899г. Семипалатинск, 1899. С. 1-33.

ДаунсД. Калифорния // Североамериканские индейцы. М.: Прогресс, 1978. С. 286-318.

Демидов С.М. К вопросу о некоторых пережитках домусульманских обрядов и верований у юго-западных туркмен // ТИИАЭ. Т. VI. Ашхабад, 1962. C. $183-219$.

Культура и быт казахского колхозного аула / Отв. ред. А.Х.Маргулан и В.В. Востров. АлмаАта: Наука, 1967. 303 с.

Полидович Ю.Б. О некоторых семиотических аспектах функционирования сосудов в погребаль- ных обрядах предскифского времени // Структурно-семиотические исследования в археологии. Том 2 / Гл. ред. А.В. Евглевский. Донецк: ДонНУ, 2005. С. 197-218.

Пошивайло О. Етнографія українського гончарства (Лівобережна Україна). Киів: Молодь, 1993. $408 \mathrm{c}$.

Свешникова Т.Н., Цивьян Т.В. К функции посуды в восточно-романском фольклоре // Из работ московского семиотического круга / Сост. Т.М.Николаева. М.: Языки русской культуры. 1997. С. 344-375.

Снитковская П.А., Усманова Э.Р. Погребальная практика петровской культуры по материалам могильника Новоильиновский II // Вестник Пермского университета. Вып. 1 (44). 2019. С.73-86. DOI: $10.17072 / 2219-3111-2019-1-73-86$

Усманова Э.Р. Могильник Лисаковский. Факты и параллели. Караганда, Лисаковск, КарГУ: 2005. $232 \mathrm{c}$.

УсмановаЭ.Р. Описание археологических объектов // Памятники Лисаковской округи: археологические сюжеты / Отв. ред. Э.Р. Усманова. Караганда, Лисаковск: Tengri Ltd, 2013. С. 20-88.

Эванс-ПричардЭ. История антропологической мысли. М.: Восточная литература. 2003. 358 c.

\section{REFERENCES}

Argynbayev, K. 1974, "Kazakh wedding and wedding ceremonies in the past and present", Sovetskaya etnografiya, no. 6, pp. 69-77. (In Russ.)

Bayburin,A.K. 1993, "Ritual in the traditional culture. Structural and semantic analysis of the East Slavic rites". Nauka, St. Petersburg, 253 p. (In Russ.)

Butanayev, V.Y. 1999, "Khakassian-Russian historical and ethnographic dictionary". Khakassia, Abakan, 240p. (In Russ.)
Gennep van, A. 1999, "The rites of passage. A systematic study of rites". Vostochnaya literature, Moscow, 198 p. (In Russ.)

Gern von, V. 1899, "From the notebooks. Ethnographic notes. The character and the customs of the Kyrgyz-Cossacks", Pamyatnaya knizhka Semipalatinskoj oblasti na $1899 \mathrm{~g}$. ("The Memorial book of the Semipalatinsk region of 1899"). Semipalatinsk, pp. 1-33. (In Russ.) 
Downs, D. 1978, "California", Severoamerikanskiye indeytsy ("North American Indians"). Moscow, pp. 286-318. (In Russ.)

Demidov, S.M. 1962, "On the question of some elements of pre-Islamic rites and beliefs among the Southwestern Turkmens", Trudy instituta istorii, arkheologii i etnografii ("Proceedings of the Institute of History, Archaeology and Ethnography"), vol.6. Ashkhabad, pp. 183-219. (In Russ.)

Suleymanov R.B., MasanovE.A., \& ArgynbaevH.A. 1967, "The culture and everyday life of the Kazakh collective farm aul". Nauka, Alma-Ata, 303 p. (In Russ.)

Polidovich, Y.B. 2005, "On some semiotic aspects of vessels functionality in the funerary rites of preScythian times", Strukturno-semioticheskiye issledovaniya $v$ arkheologii ("Structural and semiotic studies in archaeology"), vol.2. Donetsk, pp.197-218. (In Russ.)

Poshyvaylo, O. 1993, "Ethnography of the Ukrainian pottery (Left-bank Ukraine)”. Molod, Kyiv, 408 p. (In Russ.)
Sveshnikova, T.N., Tsivyan, T.V. 1997, "On the function of tableware in Eastern Roman folklore", Iz rabot moskovskogo semioticheskogo kruga ("From the works of Moscow semiotic circle"). Moscow, pp. 344-375. (In Russ.)

Snitkovskaya, P.A., Usmanova, E.R. 2019, “Funerary rites of the Petrovka culture based on the assemblages from Novoilinovsky II necropolis", Perm University Herald, no.1, vol.44. pp.73-86. doi: 10.17072/2219-3111-2019-1-73-86 (In Russ.)

Usmanova, E.R. 2005, "Lisakovsk necropolis. Facts and parallels". KarGU, Karaganda, Lisakovsk, 232 p. (In Russ.)

Usmanova,E.R. 2013, "Description of the archaeological objects", Pamyatniki Lisakovskoy okrugi: arkheologicheskiye syuzhety ("Sites of the Lisakovsk region: archaeological patterns"). Karaganda, Lisakovsk, pp. 20-88. (In Russ.)

Evans-Pritchard, E. 2003, "History of anthropological thought". Vostochnaya literature, Moscow, $358 \mathrm{p}$. (In Russ.)

\section{Сведения об авторах}

Эмма Радиковна Усманова, научный сотрудник, Сарыаркинский археологический институт Карагандинского университета им. академика Е.А.Букетова, Республика Казахстан, г. Караганда. E-mail: emmadervish2004@mail.ru, ORCID: 0000-0003-1625-5086

Зубайда Кабиевна Сураганова, кандидат исторических наук, ведущий научный сотрудник, Государственный историко-культурный музей-заповедник «Бозок», Республика Казахстан, г.НурСултан. E-mail: suraganova_zk@mail.ru, ORCID: 0000-0001-9893-6461

\section{Information About the Authors}

Emma R. Usmanova, researcher, Saryarka Archaeological Institute of the Karaganda University named after the academician Ye.A.Buketov, the Republic of Kazakhstan, Karaganda. E-mail: emmadervish2004@mail.ru, ORCID: 0000-0003-1625-5086

Zubaida K. Suraganova, Ph.D., leading researcher, State Historical and Cultural Museum Reserve "Bozoq", the Republic of Kazakhstan, Nur-Sultan. E-mail: suraganova_zk@mail.ru, ORCID: 0000-0001-98936461 